\title{
Targeted therapy in recurrent or metastatic head and neck carcinoma
}

\begin{abstract}
This review article is trying to high light the current evidence to support the use of targeted therapy for the best management practices for patients with recurrent and/ or metastatic (R/M) head and neck squamous cell carcinoma (HNSCC). Platinum based chemotherapy is the cornerstone of palliation for patients with R/M HNSCC .Platinum doublets induce higher response rates at the cost of toxicity, but do not demonstrate a survival advantage. EGFR inhibitors, including monoclonal antibodies and tyrosine kinase inhibitors, have achieved only modest success in R/M HNSCC. Immunotherapy represents an attractive treatment strategy for R/M HNSCC, with promising preliminary results. Despite therapeutic advances, prognosis remains poor for patients with $\mathrm{R} / \mathrm{M} \mathrm{HNSCC}$, illustrating the importance of identifying predictive biomarkers and finding ways to overcome mechanisms of resistance.
\end{abstract}

Volume 2 Issue | - 2018

\author{
Cessal Thommachan Kainickal \\ Division of Head \& Neck Clinical Oncology, Regional Cancer \\ Centre, India
}

\begin{abstract}
Correspondence: Cessal Thommachan Kainickal,Associate Professor, Division of Head \& Neck Clinical Oncology, Regional Cancer Centre, Trivandrum, kerala, India-6950II, Tel +91$9446800850,+9|-47|-2522379,2522297,2522486$, Fax +9| 47| 24438I4, Email drcessalthomas@gmail.com
\end{abstract}

Received: January 25, 2018 | Published: February 09, 2018

Keywords: targeted therapy, head and neck carcinoma, metastatic or recurrent disease

Abbreviations: R/M, recurrent and/or metastatic; HNSSC, head and neck squamous cell carcinoma; FU, fluorouracil; PFS, progression-free survival; OS, overall survival; EGFR, epidermal growth factor receptor; TGF- $\alpha$, transforming growth factor-alpha; $\mathrm{TKI}$, tyrosine kinase inhibitors; $\mathrm{mAb}$, monoclonal antibodies; $\mathrm{ACU}$, area under the concentration; PD 1, programmed death 1; IC, investigator's choice

\section{Introduction}

Most often, patients with head and neck squamous cell carcinoma (HNSCC) present with locally advanced-stage disease, comprising stage III to IVB disease. ${ }^{1,2}$ It is estimated that up to $60 \%$ patients develop local failure and up to $30 \%$ have risk of distant failure. ${ }^{2,3}$ Despite therapeutic advances and multimodality treatment, prognosis remains poor for patients with recurrent or metastatic HNSCC. In most of the series the median survival of patients with recurrent or metastatic head and neck squamous cell cancer is ranging from six to nine months only. ${ }^{4,5}$ Management of these patients depends on their general condition, comorbidities, initial treatment plan, and time interval to recur. Salvage surgery and/or re-irradiation are options for patients with local recurrence and many series has demonstrated prolonged survival. ${ }^{6-8}$ Systemic therapy is indicated in conjunction with best supportive care for most patients with metastatic or advanced recurrent head and neck cancer. In this subgroup, patients undergoing palliative systemic therapy for inoperable locally recurrent disease have prolonged disease-free survival compared with patients with metastatic disease. ${ }^{9}$ The choice of a systemic regimen is influenced by whether patients have received systemic agents as part of their initial management plan, time to relapse and performance status of the patient.

Treatment options include single agent therapy and combination regimens using either conventional cytotoxic chemotherapy and/ or molecularly targeted agents, combined with best supportive care. Initially Methotrexate and bleomycin were in use and by 1980s Platinum-based chemotherapy became the backbone of treatment
Later it was found that platinum doublets induce better response rates than single agents at the cost of increased toxicity, but they did not demonstrate a survival advantage. The regimens of platinum combined with fluorouracil (FU) or a taxane showed $30 \%$ response rate, median progression-free survival (PFS) of 3 to 4 months, and median overall survival (OS) of 6 to 8 months. ${ }^{10,11}$ Triplet cytotoxic regimens were subsequently tested, again survival was not improved and toxicity was considerably more compared to doublets. ${ }^{12-14}$ Later targeted therapy were developed, when added to cytotoxic chemotherapy, they resulted in a median survival time of 10 months. ${ }^{15}$ This article will review the current evidence for the use of targeted agents in recurrent or metastatic head and neck cancer.

\section{EGFR inhibitors}

Epidermal Growth Factor Receptor (EGFR) remains the most robustly studied and proven marker in head and neck cancers. Epidermal growth factor receptor (EGFR) protein expression is detected in $90 \%$ of all HNSCC tumors. ${ }^{16}$ EGFR is a $170-180 \mathrm{kd}$ trans membrane glycoprotein tyrosine kinase receptor. It binds Epidermal growth factor (EGF), Transforming growth factor-alpha (TGF- $\alpha$ ), and other regulating proteins. Activation of EGFR results in a complex cascade of signaling pathways that influence normal cellular proliferation and differentiation which lead to strong mitogenic activity. High levels of EGFR protein expression is associated with decreased survival, resistance to radiotherapy, loco regional treatment failure, and increased rates of distant metastases. ${ }^{16}$ EGFR inhibitors include monoclonal antibodies $(\mathrm{mAb})$ that block the extracellular ligand-binding domain, and small molecule inhibitors (Tyrosine kinase inhibitors -TKI) that inhibit activation of the intracellular cytoplasmic tyrosine kinase.

Cetuximab is a monoclonal antibody to the extracellular domain of EGFR and inhibits its downstream actions via multiple mechanisms. In March 2006, the US Food and Drug Administration granted approval for the addition of cetuximab to radiation therapy in locally or regionally advanced SCCHN or as monotherapy for patients with platinum-refractory, recurrent or metastatic (RM) SCCHN. This 
approval was based on a randomized phase III trial ${ }^{4}$ and a single-arm phase II trial. ${ }^{17}$ Bonner et al. ${ }^{4}$ demonstrated that the combination of cetuximab and radiation was superior to radiation alone in patients with stage III/IV SCCHN with statistically significant improvements in locoregional control (24.4 $v 14.9$ months; $P=.005)$ and overall survival (OS; 5-year OS, $45.6 \% v 36.4 \%$; $P=.018$ ).
An open-label, single-arm trial evaluated the efficacy of cetuximab in 103 patients with RM SCCHN who experienced disease progression on platinum-based therapy and demonstrated an objective response rate of $13 \%$ with a median duration of approximately 4 months. ${ }^{18}$ List of phase II trials addressing role of cetuximab in recurrent or metastatic setting is summarized in Table 1.

Table I Phase II trials addressing role of cetuximab in R/M SCCHN

\begin{tabular}{lllll}
\hline Author & Phase & Patients & Treatment & Results \\
\hline Hitt $^{19}$ & II & $46(35$ evaluable $)$ & Cetuximab/Paclitaxel & CR 24\% PR 36\% \\
Vermorken $^{18}$ & II & 103 & Cetuximab & $\begin{array}{l}\text { Median OS } \\
\text { I78 days }\end{array}$ \\
Herbst $^{20}$ & II & 155 & Cetuximab/Platinum & II.50\% \\
Baselga $^{21}$ & II & 96 & Cetuximab/Platinum & I83 days \\
\hline
\end{tabular}

From the phase II trials, it was clear that the combination of cetuximab and platinum chemotherapy is a good option and welltolerated approach to the treatment of patient population with platinum-refractory recurrent or metastatic SCCHN for whom there are no recommended standard therapeutic options. An additional indication for cetuximab was granted by the US Food and Drug
Administration in November 2011 for the treatment of recurrent or metastatic SCCHN in combination with platinum-based therapy and fluorouracil or metastatic SCCHN following progression with platinum-based chemotherapy. It was based on phase III trials mentioned in Table 2.

Table 2 Phase III trials addressing role of cetuximab in R/M SCCHN

\begin{tabular}{lllll}
\hline Author & Phase & Patients & Treatment & Results \\
\hline & & 220 & Platinum/FU & Median OS \\
Vermorken $^{15}$ & III & & & 7.4 months \\
& & 222 & Platinum/FU/cetuximab & 10.1 months* \\
& & 57 & CDDP/cetuximab & Median OS \\
Burtness $^{22}$ & III & 60 & CDDP & 9.2 months \\
& & & & 8 months
\end{tabular}

\section{EGFR-targeted therapy for first-line treatment of recurrent or metastatic $(R / M)$ CCHN}

In the phase III EXTREME trial, 442 Patients with recurrent or metastatic head and neck cancer were assigned to platinum $/ 5 \mathrm{FU}$ with or withoutcetuximab ${ }^{15}$.Patients received either cisplatin [100mg/ $\mathrm{m}^{2}$ on day 1] or carboplatin [area under the concentration $\mathrm{x}$ time curve
[AUC] of 5 day 1]) plus fluorouracil $\left(1000 \mathrm{mg} / \mathrm{m}^{2}\right.$ per day for four days) every three weeks with or without cetuximab $\left(400 \mathrm{mg} / \mathrm{m}^{2}\right.$ for the initial dose, followed by subsequent weekly $250 \mathrm{mg} / \mathrm{m}^{2}$ ). Chemotherapy was given for a maximum of six cycles, and cetuximab was continued as maintenance until disease progression or toxicity. Overall, 39 percent of patients had received systemic chemotherapy at least six months prior to randomization as part of their initial definitive management (Table 3).

Table 3 Results of EXTREME trial is summarized below

\begin{tabular}{lll}
\hline & $\begin{array}{l}\text { Cetuximab+ } \\
\text { Platinum/5-FU (N=222) }\end{array}$ & $\begin{array}{l}\text { Platinum/5-FU } \\
(\mathbf{N}=220)\end{array}$ \\
\hline Median age, yrs (range) & Median age, yrs (Range) & $57(33-78)$ \\
Male/female, \% & $89 / 11$ & $89 / 11$ \\
Loco-regional recurrence & $54 \%$ & $54 \%$ \\
Metastasis & $46 \%$ & $46 \%$ \\
Primary metastatic disease, \% & 8 & 7 \\
\hline
\end{tabular}


The trial concluded that chemotherapy plus cetuximab significantly prolonged overall survival compared with chemotherapy alone (median 10.1 versus 7.4 months, $\mathrm{P}=0.04$ ). Significant improvements were also seen in the progression-free survival and objective response rates (median 5.6 versus 3.3 months and 36 versus 20 percent, respectively). The low numbers of patients with p16 and/ or HPV positive tumours treated with chemotherapy plus cetuximab trended toward better progression-free survival, overall survival, and response rate than those who received chemotherapy alone. The overall incidence of severe (grade 3 or 4) adverse events with the cetuximab regimen was not significantly increased compared with chemotherapy alone ( 82 versus 76 percent).

5 year follow up data of Extreme trial ${ }^{23}$ showed consistent results. It was found that a total of 100 patients in the cetuximab arm who had at least stable disease received cetuximabmonotherapy until disease progression or unacceptable toxicity, with a median treatment duration of 29.9 weeks. Thirty-one (14\%) patients in the cetuximab arm and $25(11 \%)$ in the $\mathrm{CT}$ arm of the intention to treat population were deemed long-term survivors ( $>2$ years). Retrospective analysis of the trial showed that p16 and HPV status have prognostic value in recurrent or metastatic SCCHN and survival benefits of chemotherapy plus cetuximab over chemotherapy alone are independent of tumour p16 and HPV status. ${ }^{24}$

Likewise, Panitumab was tested in phase III trials in patients with recurrent or metastatic setting. In the SPECTRUM phase III trial, 657 patients were treated with cisplatin plus 5-fluorouracil, with or without Panitumumab. ${ }^{25}$ The primary objective of the trial was overall survival and there was a statistically non significant trend toward increased overall survival with the addition of Panitumumab (median 11.1 versus 9.0 months, $\mathrm{P}=0 \cdot 1403$ ). It improved progressionfree survival and had an acceptable toxicity profile. HPV status was available by p16 immunohistochemistry in $67 \%$ of patients and retrospective analysis showed benefit in terms of progression-free and overall survival for the p16 negative patients. However, this study is difficult to interpret because of the low cut-off used to define p16 positivity, the inclusion of non-oropharyngeal p16 positive patients in the analysis, and the poor correlation between 16 positivity and the presence of HPV DNA in other studies (Table 4).

Table 4 Spectrum trails and Results

\begin{tabular}{ll} 
Spectrum Trial & Results \\
$\mathrm{n}=657$ & Local PFS-Improved \\
met/rec HNSCC & OS-not significant \\
CDDP+5FU+/-Panitumumab & Benefit-HPV negative patients \\
\hline
\end{tabular}

The programmed death 1 (PD-1) inhibitor pembrolizumab demonstrated a clinically significant $24.8 \%$ overall response rate in patients with recurrent or metastatic squamous cell carcinoma of the head and neck (SCCHN),supporting further study of pembrolizumab as anticancer therapy for advanced head and neck cancers. ${ }^{26}$

\section{Targeted therapy for second-line treatment of recurrent or metastatic SCCHN}

Nivolumab is the first immune checkpoint inhibitor to demonstrate improved OS in a randomized controlled trial in platinum-refractory $\mathrm{R} / \mathrm{M}$ SCCHN compared to investigator's choice (IC) chemotherapy. ${ }^{27}$ The drug is a fully human IgG4 anti-PD-1 monoclonal antibody. patients aged $\geq 18$ yr with $\mathrm{R} / \mathrm{M}$ SCCHN and ECOG PS $0-1$ were randomized 2:1 to nivolumab $3 \mathrm{mg} / \mathrm{kg}$ q2w (until PD or toxicity) or single-agent chemotherapy (MTX, docetaxel, or cetuximab). 361 patients were randomized, 240 to nivolumab and 121 to single agent chemo. The median overall survival was 7.5 months for nivolumab ( $95 \%$ confidence interval 5.5 to 9.1 ) versus 5.1 months (95\% CI, 4.0 to 6.0) for patients who received IC chemotherapy. Overall survival was significantly longer with nivolumab than with standard therapy with significant $P$ value (hazard ratio for death, $0.70 ; 97.73 \%$ CI, 0.51 to $0.96 ; \mathrm{P}=0.01$ ). Treatment-related adverse events of grade 3 or 4 were notably low in the nivolumab group ( $13.1 \%$ versus $35.1 \%$ ).

In Phase III study of gefitinib compared with intravenous methotrexate in previously treated four hundred eighty-six patients with recurrent SCCHN were randomly assigned to oral gefitinib $250 \mathrm{mg} /$ day, gefitinib $500 \mathrm{mg} /$ day, or methotrexate $40 \mathrm{mg} /$ $\mathrm{m}^{2}$ intravenously weekly. ${ }^{28}$ Neither gefitinib 250 nor $500 \mathrm{mg} /$ day improved overall survival compared with methotrexate $(\mathrm{P}=.12$ and $\mathrm{P}=.39$, respectively). Median survival with gefitinib $250 \mathrm{mg}$ was 5.6 months, compared to, gefitinib 500mg (6.0 months), and methotrexate (6.7 months). Patients with platinum-resistant disease had a survival advantage when given methotrexate.

In Eastern Cooperative Oncology Group Trial, 270 Patients with recurrent or metastatic SCCHN with ECOG performance status of 2, or patients with ECOG performance status of 0 to 2 but were previously treated with chemotherapy, were randomly assigned to receive weekly docetaxel plus either placebo (arm A) or gefitinib $250 \mathrm{mg} / \mathrm{d}$, orally (arm B) until disease progression. ${ }^{29}$ The study was closed early at interim analysis ( $\operatorname{arm} \mathrm{A}, \mathrm{n}=136$; $\operatorname{arm} \mathrm{B}, \mathrm{n}=134)$. Median overall survival was 6.0 months in arm A versus 7.3 months in arm $\mathrm{B}(P=.60)$. An unplanned subset analysis showed that gefitinib improved survival in patients younger than 65 years (median $7.6 v 5.2$ months; $P=.04$ ). Also, there was a trend for improved survival in patients with c-MET wild-type (5.7 v 3.6 months; $P=.09$ ) regardless of treatment. Grade 3/4 toxicities were comparable between the two arms.

LUX-Head \& Neck 1 trial $^{30}$ is an open-label, phase 3, randomised controlled trial conducted in 101 centres in 19 countries between Jan 10,2012 , and Dec 12, 2013. Patients with recurrent, metastatic, or both who had progressed on or after first-line platinum-based therapy, who were not amenable for salvage surgery or radiotherapy, were randomly assigned in a $2: 1$ ratio to receive oral afatinib $(40 \mathrm{mg} /$ day, $n=322)$ or intravenous methotrexate $\left(40 \mathrm{mg} / \mathrm{m}^{2}\right.$ per week, $\left.\mathrm{n}=161\right)$. After a median follow-up of 6.7 months, progression-free survival was longer in the afatinib group than in the methotrexate group (median 2.6 months for the afatinib group vs 1.7 months for the methotrexate group; $\mathrm{p}=0.030$ ) and had a manageable safety profile. These findings provide important new insights into the treatment of this patient population and support further investigations with irreversible ERBB family blockers in HNSCC. Erlotinib, is a reversible EGFR TKI and has demonstrated modest activity as monotherapy ${ }^{31}$ and lapatinib, ${ }^{32}$ a dual EGFR/human epidermal growth factor receptor 2(HER2) inhibitor failed to show any benefit in recurrent/metastatic setting.

Dacomitinib, another irreversible pan-ErbB inhibitor (EGFR, HER2, and HER4), demonstrated a modest response rate of $12.7 \%$ and median PFS and OS times of 12.1 and 34.6 weeks, respectively, in a phase II study of dacomitinib monotherapy in 69 patients with R/M HNSCC. ${ }^{33}$ Another molecule which has gained recent momentum is Pembrolizumab (Keytruda), ananti-programmed death 1 receptor antibody. The FDA granted accelerated approval to pembrolizumab for 
patients with recurrent or metastatic HNSCC with disease progression on or after platinum-containing chemotherapyin August 2016 based on results from the open-label phase Ib KEYNOTE-012 trial. ${ }^{34}$

The phase II KEYNOTE-055 trial $^{35}$-reported by Bauml et al confirms the activity of pembrolizumab in previously platinum-and cetuximab treated recurrent or metastatic squamous cell carcinoma of the head and neck. Among 171 patients treated, 75\% received two or more prior lines of therapy for metastatic disease. Median progression-free survival was 2.1 months, and median overall survival was 8 months. $82 \%$ were PD-L1 positive, and $22 \%$ were HPV positive. Response rates were similar in all HPV and PD-L1 subgroups.

But Pembrolizumab did not meet the primary endpoint of overall survival in patients with previously-treated recurrent or metastatic head and neck squamous cell carcinoma in the phase III KEYNOTE-040 trial. ${ }^{36}$ KEYNOTE-048, a phase III trial comparing pembrolizumab with platinum-based chemotherapy plus 5-FU and cetuximab, or in combination with platinum-based therapy and 5-FU as a frontline treatment for patients with recurrent or metastatic HNSCC is ongoing.

In conclusion chemotherapy+cetuximab improves overall survival when compared to chemotherapy alone for recurrent/metastatic head and neck carcinoma and is approved as first line treatment modality. Nivolumab improves survival in platinum refractory disease compared to single agent chemotherapy. Other agents in the second line setting, Geftinib has shown comparable results to methotrexate and Afatinib has shown better progression free survival compared to methotrexate.

\section{Mechanisms of resistance to cetuximab}

Randomized trials by Bonner et $\mathrm{al}^{4}$ and EXTREME trial have demonstrated that many HNSCC patients do not respond to cetuximab, despite HNSCC being overwhelmingly EGFR-positive. In HNSCC, the mutations and alternate pathways theorized to possibly contribute to anti-EGFR resistance are numerous, including mutations in the extracellular domain (EGFRvIII) and tyrosine kinase domain, $\mathrm{K}$-ras and H-ras, mutations in epithelial-mesenchymal transition such as increased vimentin expression, decreased E-Cadherin expression, decreased Claudins 4 and 7 expression, alternate pathways such as Cyclin D1 upregulation, PTEN mutations, PI3KCA mutations, Akt Amplification $^{37}$.Elucidating these mutations and alternate pathways will be vital going forward in order to 1) combine anti-EGFR therapy synergistically with other agents and 2) predict who will respond to anti-EGFR therapy ie begin to personalize HNSCC treatment.

Another potential cause of cetuximab resistance is the EGFR variant III (EGFRvIII) a mutation found in $42 \%$ of HNSCC tumors which results in a ligand-independent activation of the receptor. ${ }^{38}$ EGFRvIII is not required to dimerize with another receptor for activation and signals downstream only through the PI3K pathway, unlike wild-type EGFR (wtEGFR). ${ }^{39}$ The binding affinity of cetuximab to EGFRvIII is much lower compared to wtEGFR, providing an explanation for resistance of some HNSCC tumors to cetuximab. Furthermore, EGFRvIII mediates tumor cell migration and invasion by increased STAT3 activation and induction of HIF1- $\alpha$, contributing to cetuximab resistance in HNSCC. Targeting this unique structure of EGFRvIII has recently become the focus of study in overcoming this resistance. ${ }^{40,41}$

Most consistent marker of response to EGFR inhibitors is clinical: development of acneiform rash. In the Bonner trial, at 5-year follow up, patients in the cetuximab arm with a prominent acneiform rash (grade 2-4) had a significantly longer overall survival than those with a mild rash (68.8 vs. 25.6 months). This may implicate the acneiform rash as a biomarker for optimal outcome with cetuximab. ${ }^{4}$ In addition to the aforementioned Bonner trial, numerous authors have reported a correlation between development of rash and response to EGFR inhibitors in various cancers including HNSCC, colorectal cancer, gynecologic and lung cancer (Table 5).

Table 5 Current trials (phase II) combining cetuximab and other agents in the treatment of recurrent or metastatic head and neck squamous cell carcinoma (HNSCC)

\begin{tabular}{|c|c|c|c|c|}
\hline Trial & Regimen & Phase & Sample size & Target \\
\hline $\begin{array}{l}\text { NCT0I040832-EMD I } 20108 \text { I with cetuximab in } \\
\text { second-line cetuximab-naïve in recurrent or metastatic } \\
\text { squamous HNSCC }\end{array}$ & $\begin{array}{l}\text { Cetuximab weekly vs. cetuximab } \\
\text { weekly+EMD I } 20108 \mid 0.32 \mathrm{mg} / \mathrm{kg} \\
\text { weekly }\end{array}$ & II & 104 & TLR9 \\
\hline $\begin{array}{l}\text { NCT00409565-Cetuximab and bevacizumab in } \\
\text { recurrent or metastatic HNSCC }\end{array}$ & $\begin{array}{l}\text { Cetuximab weekly+ bevacizumab } \\
15 \mathrm{mg} / \mathrm{kg} \text { q3 weeks }\end{array}$ & II & 48 & VEGFR \\
\hline $\begin{array}{l}\text { NCTO I } 256385 \text {-Temsirolimus with or without } \\
\text { cetuximab in patients with recurrent and/or metastatic } \\
\text { head and neck cancer who did not respond to } \\
\text { previous therapy }\end{array}$ & $\begin{array}{l}\text { Cetuximab+temsirolimus weekly vs. } \\
\text { temsirolimus weekly }\end{array}$ & II & 80 & mTOR \\
\hline $\begin{array}{l}\text { NCTOI } 3 \text { I6757-Carboplatin, paclitaxel, cetuximab, and } \\
\text { erlotinib }\end{array}$ & $\begin{array}{l}\text { Cetuximab, paclitaxel, } \\
\text { carboplatin q2I days }\end{array}$ & II & 43 & EGFR \\
\hline In metastatic or recurrent HNSCC & + daily erlotinib (starting in course 2 ) & & & \\
\hline $\begin{array}{l}\text { NCTOI0I5664-Cisplatin, cetuximab and temsirolimus } \\
\text { in recurrent or metastatic HNSCC }\end{array}$ & $\begin{array}{l}\text { temsirolimus weekly }(10,15 \text { or } 25 \\
\text { mg), cisplatin monthl+ cetuximab } \\
\text { weekly }\end{array}$ & II & 56 & mTOR \\
\hline NCTO1252628-PX-866 and Cetuximab & cetuximab+PX-866 vs. cetuximab & $1 / I I$ & 178 & $\mathrm{PI} 3 \mathrm{~K}$ \\
\hline $\begin{array}{l}\text { NCTO I 087970-Pemetrexed, cetuximab and carboplatin } \\
\text { or cisplatin in recurrent or metastatic HNSCC }\end{array}$ & $\begin{array}{l}\text { Pemetrexed, cetuximab + carboplatin } \\
\text { or Cisplatin }\end{array}$ & II & 108 & $\begin{array}{l}\text { TS, DHFR, } \\
\text { GARFT }\end{array}$ \\
\hline $\begin{array}{l}\text { NCTOI } 283334-\text { Carboplatin, cetuximab and RAD00I in } \\
\text { advanced HNSCC }\end{array}$ & Carboplatin, cetuximab + RAD00I & II & 48 & mTOR \\
\hline
\end{tabular}

Note: Taken from clinicaltrials.gov. 


\section{Complications of molecularly targeted therapy and management}

Targeted therapy is not the one without side effects. Rash is the most common side effect and has been encountered with $70 \%$ to $80 \%$, of the patients. However severity of the reaction may vary with grade 3rash in $10 \%$ of population. They start with Acne form reactions, over time recedes from face and chest to hands and feet and hairline, can also cause Nail dystrophy and fissures. Hypersensity reactions have been reported in: $3 \%$ to $5 \%$ of population. Other significant toxicities are cardiotoxicity $(<5 \%)$ and hypomagnesemia. Diarrhoea is the other common side effect seen with oral EGFR TKIs (Table 6). ${ }^{42}$

Table 6 Skin reaction algorithm

\begin{tabular}{|c|c|c|c|}
\hline Mild & $\begin{array}{l}\text { Continue EGFR inhibitor at current dose } \\
\text { and monitor for change in severity }\end{array}$ & $\begin{array}{l}\text { Topical hydrocortisone } 1 \% \text { or } 2.5 \% \text { cream and/or } \\
\text { Clindamycin I\% gel }\end{array}$ & $\begin{array}{l}\text { Reassess after } 2 \text { wks; if } \\
\text { reactions do not improve, } \\
\text { proceed to next step }\end{array}$ \\
\hline Moderate & $\begin{array}{l}\text { Continue EGFR inhibitor at current } \\
\text { dose and monitor for change in severity; } \\
\text { continue treatment of skin reaction }\end{array}$ & $\begin{array}{l}\text { Hydrocortisone } 2.5 \% \text { cream or Clindamycin } 1 \% \text { gel } \\
\text { or Pimecrolimus } 1 \% \text { cream plus Doxycycline } 100 \mathrm{mg} \\
\text { BID or Minocycline } 100 \mathrm{mg} \text { BID }\end{array}$ & $\begin{array}{l}\text { Reassess after } 2 \text { wks; if } \\
\text { reactions do not improve, } \\
\text { proceed to next step }\end{array}$ \\
\hline Severe & $\begin{array}{l}\text { Reduce EGFR inhibitor dose per label } \\
\text { and monitor for change in severity; } \\
\text { continue treatment of skin reaction }\end{array}$ & Treat as above plus Methyl prednisolone dose pack & $\begin{array}{l}\text { Reassess after } 2 \text { wks; } \\
\text { if reactions worsen, } \\
\text { dose interruption or } \\
\text { discontinuation may be } \\
\text { necessary }\end{array}$ \\
\hline
\end{tabular}

\section{Summary}

Cetuximab in combination with platinum-based combination chemotherapy is superior to chemotherapy alone in patients with recurrent or metastatic $\mathrm{HNSCC}$, and is recommended to improve overall survival, progression-free survival, and response rate. Nivolumab improves survives in the second line setting. Patients with HNSCC should continue to be offered clinical trials of novel agents aimed at improving outcomes.

\section{Acknowledgements}

None.

\section{Conflict of interest}

The author declares no conflict of interest.

\section{References}

1. Argiris A, Kramouzis MV, Raben D, et al. Head and neck cancer. Lancet. 2008;371(9625):1695-1709.

2. Seiwert TY, Cohen EE. State-of-the-art management of locally advanced head and neck cancer. Br J Cancer. 2005;92(8):1341-1348.

3. Marur S, Forastiere AA. Head and neck cancer: Changing epidemiology, diagnosis and treatment. Mayo Clin Proc. 2008;83(4):489-501.

4. Bonner JA, Harari PM, Giralt J, et al. Radiotherapy plus cetuximab for locoregionally advanced head and neck cancer: 5-year survival data from a phase 3 randomised trial, and relation between cetuximab-induced rash and survival. Lancet Oncol. 2010;11(1):21-28.

5. Katharine AR Price, Ezra E Cohen. Current treatment options for metastatic head and neck cancer. Curr Treat Options Oncol. 2012;13(1):35-46.

6. Goodwin WJ. Salvage surgery for patients with recurrent squamous cell carcinoma of upper aerodigestive tract: When do the ends justify the means? Laryngoscope. 2000;110(suppl 93):S1-18.

7. Janot F, de Raucort D, Benhamou E, et al. Randomized trial of postoperative reirradiation combined with chemotherapy after salvage surgery compared with salvage surgery alone in head and neck carcinoma. J ClinOncol. 2008;26(34):5518-5523.
8. De Crevoisier R, Bourhis J, Domenge C, et al. Full-dose reirradiation for unresectable head and neck carcinoma: Experience at the Gustave-Roussy Institute in a series of 169 patients. J Clin Oncol. 1998;16(11):35563562 .

9. Argiris $\mathrm{A}, \mathrm{Li} \mathrm{Y}$, Forastiere A. Prognostic factors and long-term survivorship in patients with recurrent or metastatic carcinoma of the head and neck. Cancer. 2004;101(10):2222-2229.

10. Gibson MK, Li Y, Murphy B, et al Randomized phase III evaluation of cisplatin plus fluorouracil versus cisplatin plus paclitaxel in advanced head and neck cancer (E1395): An intergroup trial of the eastern cooperative oncology group. J Clin Oncol. 2005;23(15):3562-3567.

11. Colevas AD. Chemotherapy options for patients with metastatic or recurrent squamous cell carcinoma of the head and neck. J Clin Oncol. 2006;24(17):2644-2652.

12. Shin DM, Glisson BS, et al. Phase II trial of paclitaxel, ifosfamide, and cisplatin in patients with recurrent head and neck squamous cell carcinoma. J Clin Oncol. 1998;16(4):1325-1330.

13. Janinis J, Papadakou M, Xidakis E, et al. Combination chemotherapy with docetaxel, cisplatin, and 5-fluorouracil in previously treated patients with advanced/recurrent head and neck cancer: A phase II feasibility study. Am J Clin Oncol. 2000;23(2):128-131.

14. Shin DM, Khuri FR, Glisson BS, et al. Phase II study of paclitaxel, ifosfamide, and carboplatin in patients with recurrent or metastatic head and neck squamous cell carcinoma. Cancer. 2001;91(7):1316-1323.

15. Vermorken JB, Mesia R, Rivera F, et al. Platinum-based chemotherapy plus cetuximab in head and neck cancer. N Engl J Med. 2008;359(11):11161127.

16. Ang KK, Berkey BA, Tu X, et al. Impact of epidermal growth factor receptor expression on survival and pattern of relapse in patients with advanced head and neck carcinoma. Cancer Res. 2002;62(24):7350 7356.

17. Bonner JA, Harari PM, Giralt J, et al. Radiotherapy plus cetuximab for squamous-cell carcinoma of the head and neck. $N$ Engl J Med. 2006;354(6):567-578.

18. Vermorken JB, Trigo J, Hitt R, et al. Open-label, uncontrolled, multicenter phase II study to evaluate the efficacy and toxicity of cetuximab as a single agent in patients with recurrent and/or metastatic squamous cell carcinoma of the head and neck who failed to respond to platinum-based therapy. J Clin Oncol. 2007;25(16):2171-2177. 
19. Hitt R, Irigoyen A, Nunez J, et al. Phase II study of combination cetuximab and weekly paclitaxel in patients with metastatic/recurrent squamous cell carcinoma of head and neck (SCCHN). Ann Oncol. 2007;3(4):1016-1022.

20. Herbst RS, Arquette M, Shin DM, et al. Phase II multicenter study of the epidermal growth factor receptor antibody cetuximab and cisplatin for recurrent and refractory squamous cell carcinoma of the head and neck J Clin Oncol. 2005;23(24):5578-5587.

21. Baselga J, Trigo JM, Bourhis J, et al. Phase II multicenter study of the antiepidermal growth factor receptor monoclonal antibody cetuximab in combination with platinum-based chemotherapy in patients with platinum-refractory metastatic and/or recurrent squamous cell carcinoma of the head and neck. J Clin Oncol. 2005;23(24):5568-5577.

22. Burtness B, Goldwasser MA, Flood W, et al. Phase III randomized trial of cisplatin plus placebo compared with cisplatin plus cetuximab in metastatic/recurrent head and neck cancer: an eastern cooperative oncology group study. J Clin Oncol. 2005;23(34):8646-8654.

23. Jan Baptist Vermorken, Eva Remenar, et al. Platinum-based chemotherapy (CT) plus cetuximab in recurrent or metastatic squamous cell carcinoma of the head and neck cancer (R/M-SCCHN): 5-year follow-up data for the extreme trial. J Clin Oncol. 2014;32:5.

24. Vermorken JB, Psyrri A, Mesía R, et al. Impact of tumor HPV status on outcome in patients with recurrent and/or metastatic squamous cell carcinoma of the head and neck receiving chemotherapy with or without cetuximab: retrospective analysis of the phase III EXTREME trial. Ann Oncol. 2014;25(4):801-807.

25. Vermorken JB, Stöhlmacher-Williams J, Davidenko I, et al. Cisplatin and fluorouracil with or without panitumumab in patients with recurrent or metastatic squamous-cell carcinoma of the head and neck (SPECTRUM): an open-label phase 3 randomised trial. Lancet Oncol. 2013;14(8):697710 .

26. Tanguy Y Seiwert, Barbara Burtness, Ranee Mehra, et al. Safety and clinical activity of pembrolizumab for treatment of recurrent or metastatic squamous cell carcinoma of the head and neck (KEYNOTE-012): an open-label, multicentre, phase 1b trial. Lancet Oncol. 2016;17(7):956965.

27. Gillison ML, Blumenschein G, Fayette J, et al. Nivolumab for recurrent squamous-cell carcinoma of the head and neck. $N$ Engl J Med. 2016;375(19):1856-1867.

28. Stewart JS, Cohen EE, Licitra L, et al. Phase III study of gefitinib compared with intravenous methotrexate for recurrent squamous cell carcinoma of the head and neck. J ClinOncol. 2009;27(11):1864-1871.

29. AthanassiosArgiris, Ghebremichael M, Gilbert J, et al. Phase III randomized, placebo-controlled trial of docetaxelwith or without gefitinib in recurrent or metastatic head and neck cancer: an eastern cooperative oncology group trial. J Clin Oncol. 2013;31(11):1405-1414.

30. Machiels JP, Haddad RI, Fayette J, et al. Afatinib versus methotrexate as second-line treatment in patients with recurrent or metastatic squamouscell carcinoma of the head and neck progressing on or after platinumbased therapy (LUX-Head \& Neck 1): an open-label, randomised phase 3 trial. Lancet Oncol. 2015;16(5):583-594.
31. Soulieres D, Senzer NN, Vokes EE, et al. Multicenter phase II study of erlotinib, an oral epidermal growth factor receptor tyrosine kinase inhibitor, in patients with recurrent or metastatic squamous cell cancer of the head and neck. J Clin Oncol. 2004;22(1):77-85.

32. de Souza JA, Davis DW, Zhang Y, et al. A phase II study of lapatinib in recurrent/metastatic squamous cell carcinoma of the head and neck. Clin Cancer Res. 2012;18(8):2336-2343.

33. Abdul Razak AR, Soulières D, Laurie SA, et al. A phase II trial of dacomitinib, an oral pan-human EGF receptor (HER) inhibitor, as firstline treatment in recurrent and/or metastatic squamous-cell carcinoma of the head and neck. Ann Oncol. 2013;24(3):761-769.

34. Tanguy Y Seiwert, Barbara Burtness, Ranee Mehra, et al. Safety and clinical activity of pembrolizumab for treatment of recurrent or metastatic squamous cell carcinoma of the head and neck (KEYNOTE-012): an open-label, multicentre, phase $1 \mathrm{~b}$ trial. The Lancet oncology. 2016;17(7):956-965.

35. Joshua Bauml, Tanguy Y Seiwert, David G, et al. Pembrolizumab for platinum- and cetuximab-refractory head and neck cancer: results from a single-arm, phase II study. J Clin Oncol. 2017;35(14):1542-1549.

36. Cohen EE, Harrington KJ, Le Tourneauetal C, et al. Pembrolizumab (pembro) vs standard of care (SOC) for recurrent or metastatic head and neck squamous cell carcinoma (R/M HNSCC): Phase 3 KEYNOTE-040 trial(NCT02252042). Annals of Oncology. 2017;28(5).

37. Chen LF, Cohen EW, Grandis GR. New strategies in head and neck cancer: understanding resistance to epidermal growth factor receptor inhibitors. Clin Cancer Res. 2010;16(9):2489-2495.

38. Huang HS, Nagane M, Klingbeil CK, et al. The enhanced tumorigenic activity of a mutant epidermal growth factor receptor common in human cancers is mediated by threshold levels of constitutive tyrosine phosphorylation and unattenuatedsignaling. J Biol Chem. 1997;272(5):2927-2935.

39. Sok JC, Coppelli FM, Thomas SM. Mutant epidermal growth factor receptor (EGFRvIII) contributes to head and neck cancer growth and resistance to EGFR targeting. Clin Cancer Res. 2006;12(17):5064-5073.

40. Chu CT, Everiss KD, Wikstrand CJ, et al. Receptor dimerization is not a factor in the signalling activity of a transforming variant epidermal growth factor receptor (EGFRvIII). Biochem J. 1997;324(Pt 3):855-861.

41. Moscatello DK, Montgomery RB, Sundareshan P, et al. Transformational and altered signal transduction by a naturally occurring mutant EGF receptor. Oncogene. 1996;13(1):85-96.

42. Lynch TJ, Kim ES, Eaby B, et al. Epidermal growth factor receptor inhibitor-associated cutaneous toxicities: an evolving paradigm in clinical management. Oncologist. 2007;12(5):610-621. 